\title{
Fire Risk Assessment in Selected Commercial Buildings in Mashhad, Iran, Based on NFPA 101 Standard in 2018
}

\author{
Amir Kermani Hesarshahabi $i^{1} \mathbb{D}$, Ramazan Mirzaei $^{2} \mathbb{D}$, Reza Gholamnia $^{3}$
}

Date of submission: 05 Jun. 2019, Date of acceptance: 11 Aug. 2019

\begin{abstract}
Original Article
Abstract

INTRODUCTION: Fires in residential buildings, commercial complexes, and small and large industries cause a lot of financial, human, and environmental damage in different communities annually. This study is conducted with the aim to evaluate the fire risk in the selected commercial buildings in Mashhad, Iran.

METHODS: This was a descriptive-cross-sectional and applied study conducted in the spring of 2019 on 10 separate commercial buildings in Mashhad. First, the necessary checklists for fire risk assessment from the NFPA 101 standard were prepared and compiled by the researcher, and the necessary information was completed according to the field surveys and obtaining the urban planning documents of the buildings. The information collected was then analyzed in the Computerized Fire Safety Evaluation System (CFSES) software for final evaluation of the buildings.

FINDINGS: In general, the total number of commercial buildings examined (10 cases) was in an unacceptable condition in all three areas of fire risk, including the fire control, exit, and general safety aspects. In addition, the fire risk situation in older buildings ( 5 cases) was worse than in new buildings ( 5 cases).

CONCLUSION: The fire risk assessment score of the commercial buildings studied in terms of fire control, exit route, and general safety aspects was unacceptable and none of the buildings evaluated obtained the minimum safety score in these three aspects. Therefore, to improve fire safety in commercial buildings, valid fire safety regulations and standards, including NFPA 101, must be observed to prevent fire accidents and irreparable financial and human losses.
\end{abstract}

Keywords: Fire; Safety; Building; Risk

How to cite this article: Kermani Hesarshahabi A, Mirzaei R, Gholamnia R. Fire Risk Assessment in Selected Commercial Buildings in Mashhad, Iran, Based on NFPA 101 Standard in 2018. Sci J Rescue Relief 2019; 11(3): 184-91.

\section{Introduction}

$\mathrm{T}$ The occurrence of fires in residential buildings, commercial complexes, and small and large industries causes a lot of financial, human, and environmental damage to different communities annually (1).

In Iran, about 1,400 individuals are killed in fires every year, and more than 4,500 ones are severely injured, in addition to billions of tomans of financial damage inflicted on society (2).

According to statistics released by the
American National Fire Protection Association, there were 1,342,000 fires in the United States in 2016, killing 3,390 people, injuring 14,650, and causing an estimated \$ 10.6 billion of direct financial losses. In other words, for every 2 hours and 35 minutes, one person died, and for every 35 minutes and 54 seconds, one person was injured as a result of fires (3).

Given the available information, half of all fire deaths take place in building fires, so the first step in fire safety is to assess the risk to assess the

\footnotetext{
1- Department of Health, Safety and Environment Management, School of Engineering, Tehran Branch, Islamic Azad University E-Campus, Tehran, Iran

2- PhD, Social Determinants of Health Research Center, Mashhad University of Medical Sciences, Mashhad, Iran

3- Department of Health Sciences, School of Health, Safety and Environment, Shahid Beheshti University of Medical Sciences, Tehran, Iran Correspondence to: Ramazan Mirzaei, Email: rammir277@gmail.com
} 
current situation, identify hazards, and prioritize the actions required to upgrade the safety level (2).

Risk assessment and management techniques are among the most effective and determining methods for identifying and controlling fire risk. It is also possible to determine the most important causes of fire in the buildings in terms of preference using the fire risk assessment techniques and then perform control measures in accordance with the importance of each of the causes (4).

Fire risk assessment helps security officials identify the risk hotspots well and take the necessary technical and managerial measures to minimize the risk of fire (5).

In fact, fire risk assessment provides technical principles for management's decision-making on the selection of fire protection systems (6).

The city of Mashhad, Iran is the second largest religious metropolis in the world due to the presence of the holy shrine of Ali Ebn Musa alReza (AS) and currently has a fixed population of $3,000,000$ and a floating population of domestic and foreign pilgrims of $27,000,000$ per year. Moreover, over 300 commercial complexes in Mashhad provide activities and commercial needs of this city (7).

In recent years, fires in commercial buildings have caused extensive damage and casualties, indicating their low level of fire safety. Using the Computerized Fire Safety Evaluation System (CFSES) software, which has been designed based on the NFPA 101 standard $(8,9)$, factors affecting the occurrence of building fires can be identified, and the fire safety status of the building can be assessed. This software also offers recommendations for reducing the risk of building to acceptable levels (4).

There are many similar models and software for fire risk assessment, most of which using the same evaluation models, including Fire Evaluation and Risk Assessment System (FIERA), Center for Environment Safety and Risk Engineering (CESARE), Computation of Risk Indices by Simulation Procedures (CRISP II), Fire Risk Assessment Method for Engineer (FRAME), etc. $(10,11)$.

In a study conducted by Mahdinia et al. in order to provide a software method for using risk assessment in optimizing building fire protection measures, they concluded that using quantitative risk assessment in designing and implementing fire protection systems in buildings is a suitable tool to increase efficiency. Using this software, the selected protection methods will be more appropriate and efficient. Besides, the building fire risk is managed more easily and carefully (11).

Among the studies conducted in the field of fire risk assessment using the CFSES software according to NFPA101 standard, the study by Jahangiri et al. (12) in the selected hospitals affiliated to Shiraz University of Medical Sciences, Shiraz, Iran can be mentioned. In this study, fire safety aspects in three areas of general safety $(56.25 \%)$, fire control $(87.5 \%)$, and exits $(6.25 \%)$ were acceptable and it was concluded that the exit aspect in hospitals was of a more unsafe status compared to other cases. Therefore, the necessary safety measures in these areas had to be taken in compliance with the standard and technical criteria to enhance the safety level in such buildings.

In another study, which was carried out by Rezaei et al. in the selected four-star hotels in Mashhad based on the FRAME technique, it was concluded that all the hotels surveyed did not fully comply with the national building regulations, fire regulations, and construction engineering regulations (13).

In general, the provisions of the Fire Safety Act are to provide a level of safety that restricts the onset and spread of fires and prevents the building from collapsing due to fire, and allows residents to evacuate safely, in addition, it allows the fire and rescue personnel to enter the building and extinguish the fire (14).

Based on the above issues and according to the research performed by the researcher in the scientific-research centers in the country, it was observed that there is no study in the area of assessment of fire risk in buildings with only commercial use in Mashhad using NFPA101 standard. Therefore, this study was conducted with the aim of assessing the fire risk of commercial buildings in Mashhad using CFSES software in 2018.

\section{Methods}

This was a descriptive-cross-sectional and applied study accomplished in 2018 on 10 selected and separate buildings with only commercial use in different parts of Mashhad. According to the statistics obtained from the executive working group of Mashhad commercial complexes and also the statistics of Mashhad municipality, there are over 330 commercial complexes in Mashhad, most of which have combined uses, i.e. commercial- 
administrative, commercial-residential, etc. uses. Therefore, considering that one of the main criteria of this study was buildings with only commercial uses, referring to the urban planning specifications available in Mashhad Municipality's urban planning system and real estate documents and matching information with the current situation, 10 buildings with only a commercial use in different parts of Mashhad (almost all buildings the owners of which cooperated in the assessment process) were selected as the sample volume for the study. Overall, the total number of buildings surveyed included 63 floors, with an area of approximately $213,767 \mathrm{~m}^{2}$ and the occupancy rate of 38,172 people. Of these buildings, 5 were new buildings ( 8 years old and less) and the other 5 were old (more than 8 years old) (the 8 year period was determined by software standards).

To conduct the study, the information needed to assess the fire safety status of the commercial buildings was first extracted from the CFSES software based on the NFPA101 standard, and prepared and compiled by the researcher as a checklist. The first part of this checklist included background information such as building name, height, age, number of floors, total building area, evaluator, and evaluation time, and the second part included basic measures and included 12 parameters effective in the fire safety of buildings. These 12 parameters consisted of the building structure, risk separation, vertical pores, automatic sprinkler, fire alarm, smoke detection, interior surface covering materials, smoke control, exit access, exit system, room/hallway separation, and emergency response program. In order to complete the prepared checklists, beside controlling the urban planning documents of the selected buildings available in the municipality, such as land use, building permit and completion certificate, the researcher referred to the desired commercial buildings in person and while examining the location, collected the required information. The information obtained was then transferred to CFSES software to assess the safety status of the building sites. This software gives the risk assessment results in three areas of fire control, exits, and general safety. In order to assess the fire risk of the commercial buildings after entering the background information (height, age, number of stories, etc.) in the software, the software first calculates the score that the building should obtain in the three aspects of fire control, exit routes, and general safety (minimum score required). In the next step, the software calculates the score of each building under study from the three aspects based on the fire safety variables (basic measures), and by comparing the score obtained with the minimum score required in these cases, the building fire risk is determined. Thus, if the risk score (the difference between the obtained score and the minimum score required for building safety) is greater than or equal to zero, the risk is shown to be passed and otherwise shown to be failed. In this study, in order to observe some considerations, the names of the commercial buildings were not mentioned and a coding system was used for this purpose. Table 1 provides information on all buildings under study, including total area, age, occupancy rate, number of people, building height, and number of floors. Since the structure of this software is designed to assess fire risk in commercial buildings, in this study, fire risk assessment was performed on buildings with purely commercial use so that the results have a high reliability.

Table 1. Status of commercial buildings under study based on age, height, acronym code, approximate area, and occupancy rate

\begin{tabular}{|c|c|c|c|c|c|}
\hline Project code & $\begin{array}{c}\text { Total number of } \\
\text { floors }\end{array}$ & $\begin{array}{l}\text { Height from } \\
\text { ground level }(\mathrm{m})^{* * *}\end{array}$ & $\begin{array}{l}\text { Building } \\
\text { area }\left(\mathrm{m}^{2}\right)\end{array}$ & $\begin{array}{c}\text { Occupancy } \\
\text { rate/Number of people }\end{array}$ & $\begin{array}{l}\text { Building } \\
\text { age }\end{array}$ \\
\hline A & 8 & 30 & 48243 & 8615 & New \\
\hline $\mathrm{B}$ & 8 & 24 & 20357 & 3635 & New \\
\hline $\mathrm{C}$ & 9 & 22 & 7002 & 1250 & Old \\
\hline $\mathrm{D}$ & 9 & 22 & 10620 & 1897 & New \\
\hline $\mathrm{E}$ & 5 & 20 & 25734 & 4595 & Old \\
\hline $\mathrm{F}$ & 5 & 17.5 & 37359 & 6671 & New \\
\hline $\mathrm{G}$ & 6 & 15 & 5074 & 906 & New \\
\hline $\mathrm{H}$ & 4 & 12 & 1784 & 319 & New \\
\hline I & 5 & 12 & 3660 & 654 & Old \\
\hline $\mathrm{J}$ & 4 & 10 & 4412 & 788 & Old \\
\hline
\end{tabular}




\section{Findings}

The overall results of the fire risk assessment based on the CFSES software suggested that in terms of the fire control, exit, and general safety aspects, the fire risk assessment score was unacceptable (Failed) in all commercial buildings studied, and in the three areas mentioned, respectively the general safety, exit routes, and fire control were in a worse status in terms of the score obtained in the software, and none of the commercial buildings surveyed received the minimum safety score in the three areas of fire control, general safety, and exit routes. The status of the fire safety variables in the commercial buildings investigated in Mashhad based on NFPA 101 can be observed in Table 2.

Table 2. Status of fire safety variables in the commercial buildings studied based on NFPA 101 in 2018 in Mashhad, Iran

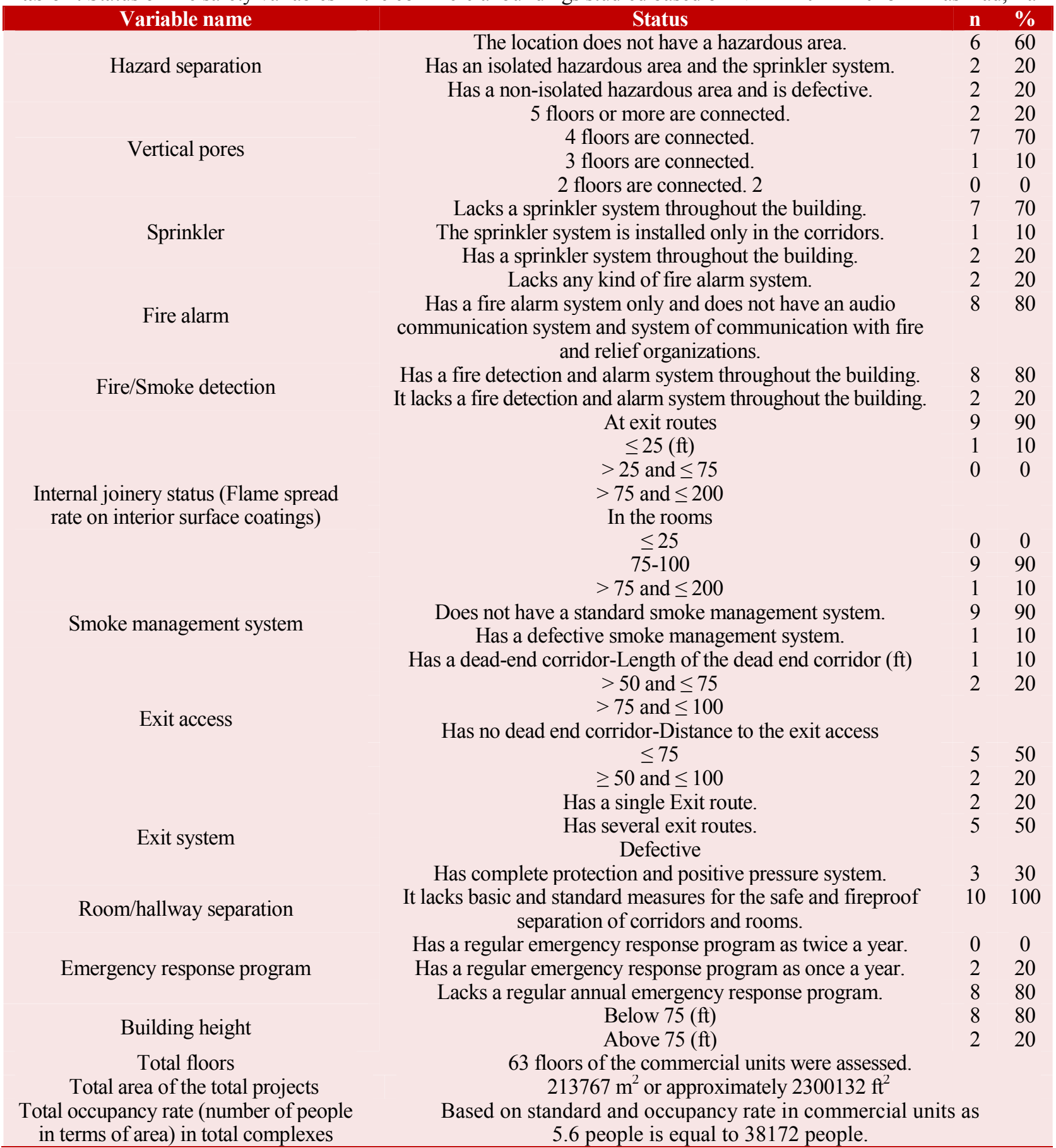


Given Table 3, Building B had a higher level of safety than other buildings due to the low score difference in the three areas of general safety, fire control, and exits with the desired fire safety score, and Building $G$ with the highest score difference in the three areas was the most unsafe building. According to Table 3, the total average difference between the desired and obtained scores in the three areas of general safety, fire control, and exit routes in old buildings was 49.5, which is $\mathbf{3 7 . 5}$ more than that of the new buildings, indicating that older buildings had a lower fire safety compared to the new ones. Furthermore, on the basis of the information presented in Table 3, in all the buildings under study in the three safety aspects, the values of the safety scores obtained differ from the standard values and are unacceptable. Among these, general safety, exits, and fire control, respectively, had the highest average score difference with the standard score in terms of fire safety.

Figures 1 and 2 show that buildings $B$ and $G$ have the best and worst conditions in terms of general safety and fire control, respectively.

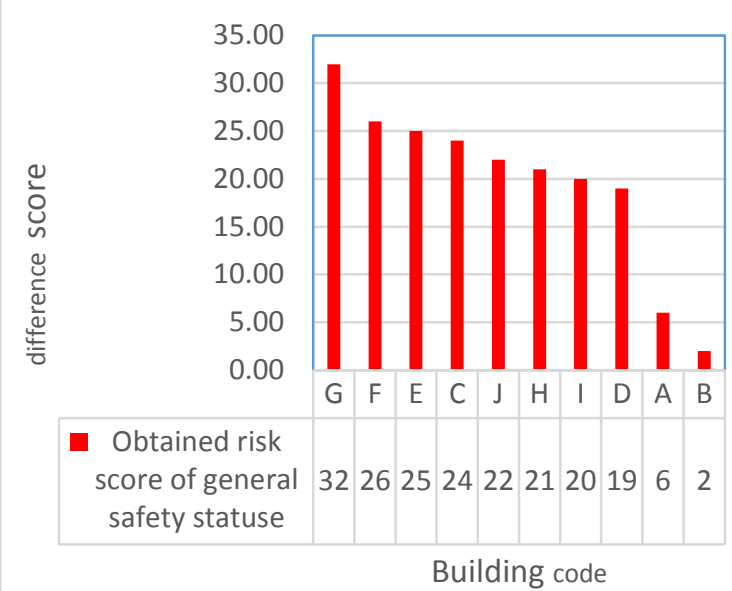

Figure 1. Comparison of safety score difference (risk score) obtained and required regarding general safety status by building based on NFPA 101 in commercial buildings in Mashhad, Iran

Table 3. Required and obtained safety scores of the commercial buildings studies based on NFPA 101 standard

\begin{tabular}{|c|c|c|c|c|c|c|c|c|c|c|}
\hline \multirow[t]{2}{*}{$\begin{array}{l}\text { Safety score } \\
\text { Building } \\
\text { code }\end{array}$} & \multicolumn{3}{|c|}{$\begin{array}{l}\text { Required fire } \\
\text { safety score }\end{array}$} & \multicolumn{3}{|c|}{$\begin{array}{l}\text { Obtained fire } \\
\text { safety score }\end{array}$} & \multicolumn{3}{|c|}{$\begin{array}{c}\text { Difference between the } \\
\text { required and obtained fire } \\
\text { safety scores }\end{array}$} & \multirow[t]{2}{*}{$\begin{array}{c}\text { Total } \\
\text { difference }\end{array}$} \\
\hline & $\begin{array}{l}\text { General } \\
\text { safety }\end{array}$ & $\begin{array}{c}\text { Fire } \\
\text { control }\end{array}$ & $\begin{array}{c}\text { Exit } \\
\text { status }\end{array}$ & $\begin{array}{c}\text { General } \\
\text { safety }\end{array}$ & $\begin{array}{c}\text { Fire } \\
\text { control }\end{array}$ & $\begin{array}{c}\text { Exit } \\
\text { status }\end{array}$ & $\begin{array}{c}\text { General } \\
\text { safety }\end{array}$ & $\begin{array}{c}\text { Fire } \\
\text { control }\end{array}$ & $\begin{array}{c}\text { Exit } \\
\text { status }\end{array}$ & \\
\hline A & 10 & 7.5 & 9.5 & 4 & 1 & 4.5 & 6 & 6.5 & 5 & 17.5 \\
\hline B & 10 & 7.5 & 9.5 & 8 & 6 & 6.5 & 2 & 1.5 & 3 & 6.5 \\
\hline $\mathrm{C}$ & 2 & 0 & 2 & -22 & -15 & -12.5 & 24 & 15 & 14.5 & 53.5 \\
\hline D & 6 & 2.5 & 4 & -13 & -5 & -11.5 & 19 & 7.5 & 15.5 & 42 \\
\hline $\mathrm{E}$ & 2 & 0 & 2 & -23 & -11 & -18 & 25 & 11 & 20 & 56 \\
\hline $\mathrm{F}$ & 6 & 2.5 & 4 & -20 & -8.5 & -14 & 26 & 11 & 18 & 55 \\
\hline G & 6 & 2.5 & 4 & -26 & -14 & -14 & 32 & 16.5 & 18 & 66.5 \\
\hline $\mathrm{H}$ & 0 & 0 & 0 & -21 & -13 & -13 & 21 & 13 & 13 & 47 \\
\hline I & 0 & 0 & 0 & -20 & -13 & -12.5 & 20 & 13 & 12.5 & 45.5 \\
\hline $\mathrm{J}$ & 0 & 0 & 0 & -22 & -14 & -10 & 22 & 14 & 10 & 46 \\
\hline \multicolumn{7}{|c|}{$\begin{array}{l}\text { Average difference between the required and obtained fire safety } \\
\text { scores in the three areas of fire control, exit routes, and general safety } \\
\text { in all buildings studied }\end{array}$} & 19.7 & 10.9 & 13 & - \\
\hline \multicolumn{7}{|c|}{$\begin{array}{l}\text { Average difference between the required and obtained fire safety } \\
\text { scores in the three areas of fire control, exit routes, and general safety } \\
\text { in older buildings ( } 5 \text { cases) }\end{array}$} & 22.4 & 13.2 & 14 & - \\
\hline \multicolumn{7}{|c|}{$\begin{array}{l}\text { Average difference between the required and obtained fire safety } \\
\text { scores in the three areas of fire control, exit routes, and general safety } \\
\text { in new buildings ( } 5 \text { cases) }\end{array}$} & 17 & 8.6 & 11.9 & - \\
\hline \multicolumn{7}{|c|}{$\begin{array}{l}\text { Average total difference between the required and obtained fire safety } \\
\text { scores in the three areas of fire control, exit routes, and general safety } \\
\text { in older buildings ( } 5 \text { cases) }\end{array}$} & \multicolumn{3}{|c|}{49.5} & - \\
\hline \multicolumn{7}{|c|}{$\begin{array}{l}\text { Average total difference between the required and obtained fire safety } \\
\text { scores in the three areas of fire control, exit routes, and general safety } \\
\text { in new buildings ( } 5 \text { cases) }\end{array}$} & \multicolumn{3}{|c|}{37.5} & - \\
\hline
\end{tabular}




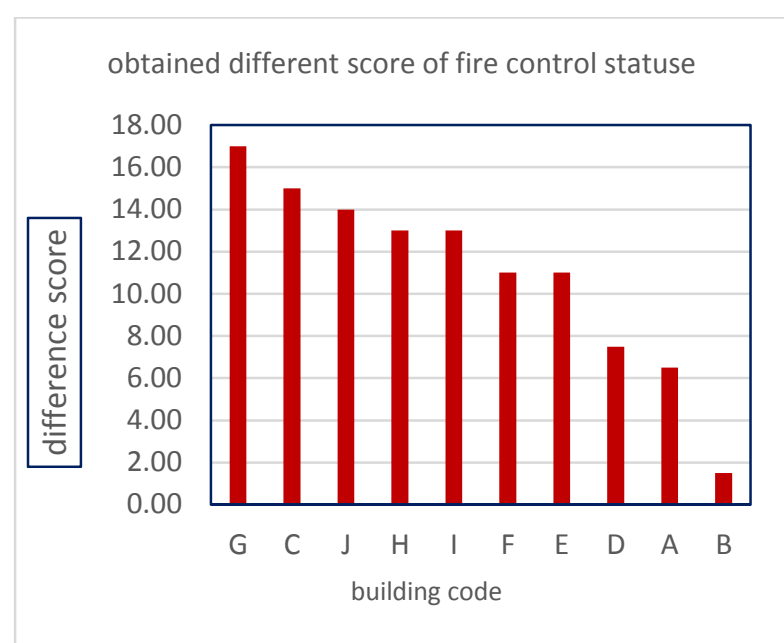

Figure 2. Comparison of safety score difference (risk score) obtained and required regarding fire control status by building based on NFPA 101 in commercial buildings in Mashhad, Iran

Figure 3 indicates that buildings $\mathrm{B}$ and $\mathrm{E}$ have the best and worst conditions in terms of the exit status, respectively.

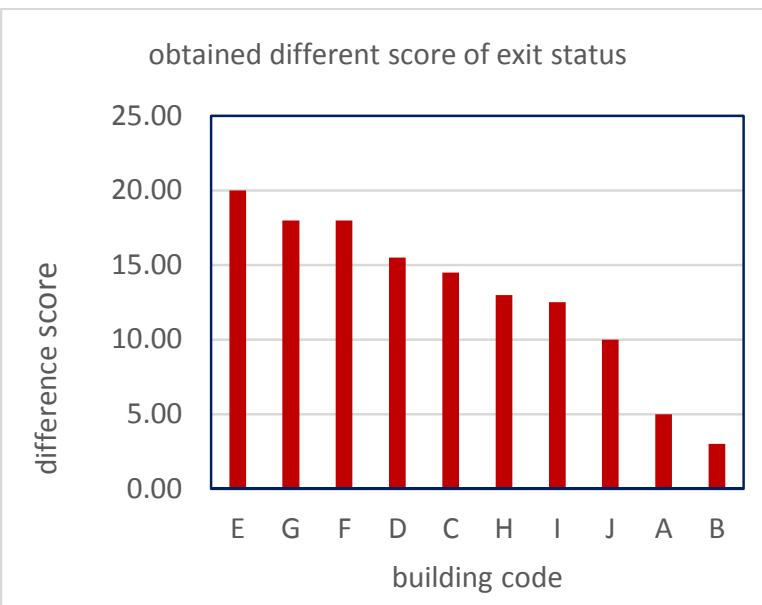

Figure 3. Comparison of safety score difference (risk score) obtained and required regarding exit status by building based on NFPA 101 in commercial buildings in Mashhad, Iran

Figure 4 displays a comparison of the average score of the new and old buildings in terms of general safety, fire control, and exits based on NFPA 101. Given the findings, in the three aspects, the old commercial buildings were in a more unsafe condition in comparison to the new commercial buildings.

\section{Discussion and Conclusion}

The present study was conducted to assess fire risk based on NFPA 101 on 63 floors of buildings with a total area of approximately $213,767 \mathrm{~m}^{2}$ (equivalent to 2,300,132 $\mathrm{ft}^{2}$ ) and for occupancy rate of 38,172 people.

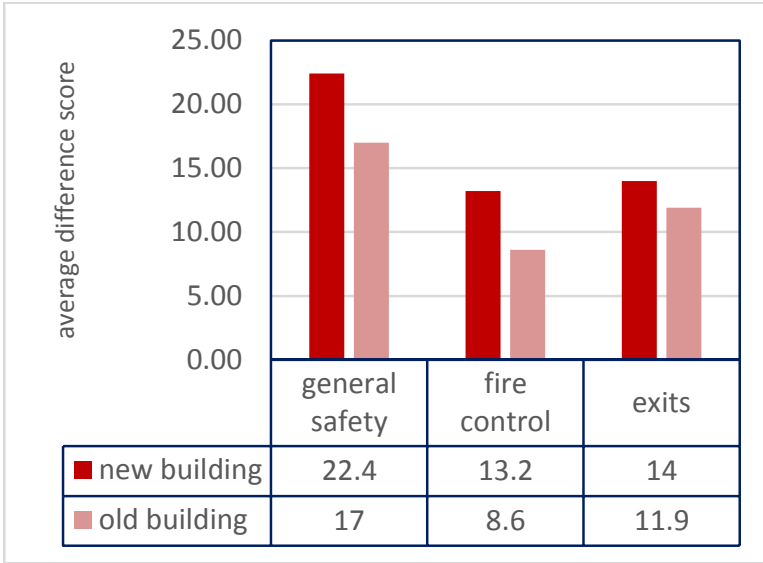

Figure 4. Comparison of the average score difference between new and old buildings in three aspects of general safety, fire control, and exits based on NFPA

101 in commercial buildings in Mashhad, Iran

The findings revealed that in the areas of fire control, exit routes, and general safety, none of the buildings surveyed had an acceptable fire risk status, and each building score was different from the minimum safety score required to some extent. The structure of the buildings had the highest impact on their final fire safety score compared to other variables. Non-flammable materials were applied for partitioning, roof, and floor in all the buildings studied and the structure of none of them was protected against fire based on the standards. This finding is in line with the results of the study conducted by Rezaei et al. (13) on the selected four-star hotels of Mashhad based on the FRAME technique, so in the event of a fire in such buildings, their demolition is not unexpected. Vertical pores between floors (such as communication channels, electrical and substairs, voids and atria, etc.) in all the studied buildings do not have the necessary fire protection. These pores cause the transfer of smoke and heat between the floors and plays an important role in the internal expansion of the fire; these findings are also consistent with the findings of the study by Jahangiri et al. (12) in Shiraz hospitals in this regard. It was also found that $90 \%$ of the buildings lacked a smoke control 
system, and only one case had an imperfect smoke control system. This study is consistent with the results obtained from Jahangiri et al. (12), whose $100 \%$ of the buildings studied lacked a smoke management system. During a fire in a building, the purpose of the smoke management system is to create a safe passage for the occupants of the building. According to statistics, up to $80 \%$ of fire deaths are related to smoke and gases (15).

Given the findings of this study, the automatic sprinkler fire protection system is used in only $30 \%$ of commercial buildings and $70 \%$ of them do not have this system. The results in this regard are in agreement with the studies by Jahangiri et al. (12) and Rezaei et al. (13). Investigations have shown that $80 \%$ of the buildings studied are equipped with an automatic fire detection system in all spaces, and only $20 \%$ lack this system. The findings of Rezaei et al. (13) showed that all the hotels they studied were equipped with a fire detection system. Therefore, it was found that the use of fire detection systems in residential buildings was considered more than commercial buildings. This equipment plays a crucial role in detecting and controlling fires. If firefighters are not notified with timely alarm systems, it will be difficult to control the fire due to its progressive spread. Therefore, the timely detection and announcement of fires will play an important role in controlling damages (5).

Materials and products used for joinery in the exit routes are of building materials (such as plaster, cement, brick, etc.) in $90 \%$ of cases that have the lowest rate of flame expansion, but the materials and products used for joinery and the decoration of the rooms are made of different types of wood, etc. in $90 \%$ of the cases, which have a high flame spread rate, and in case of fire, its expansion speed will be high.

In $30 \%$ of the commercial buildings studied, access to the exits is difficult, and in $70 \%$ of the buildings, the exits were not suitable. In the study by Jahangiri et al. (12), $56.25 \%$ of the residents' access to exit, as well as $43.75 \%$ of the exit routes were in poor and unacceptable condition. A study by Rezaei et al. (13) suggested that safety was not observed in exit routes in any of the hotels studied. Therefore, evaluators should pay more attention to this issue.

The lack of proper separation between rooms and corridors causes the internal expansion of fires in buildings; in the current study, all buildings under study lacked principled and standard measures regarding the safe and resistant separation of the rooms and corridors, which should be observed in buildings to comply with the fire safety principles. The results of this study also showed that $80 \%$ of commercial buildings do not have any regular annual emergency response program, and only $20 \%$ of the buildings had an irregular emergency response program.

In the study by Mahdinia et al. (16), which was performed in the hospital admission ward in Qom, Iran, it was found that there was no specific plan for emergency measures and rescue of people and equipment, and in the study of Jahangiri et al. (12) it was found that $31.25 \%$ of the buildings lacked an emergency response programs, and in other buildings, the emergency response maneuvers were performed without the presence of relevant organizations.

Taking into account the information presented in Table 2, in all the buildings studied in the three aspects of general safety, fire control, and exits, the obtained safety score values were far from the standard values and were unacceptable (Failed). Among them, general safety, exits, and fire control respectively had the highest average difference in scores compared to the standard score in terms of fire safety. In the study by Jahangiri et al., an unacceptable result was obtained in $43.75 \%$ of buildings in the field of general safety (12).

The results of a case study of fire risk assessment in multi-story commercial buildings according to NFPA101 standard in Shiraz also showed that the fire safety situation in the studied buildings was undesirable (17).

Regarding the fire risk level, the commercial buildings studied had the worst safety situation in the area of exits following general safety. In the study by Jahangiri et al. (12), in $93.75 \%$ of the buildings surveyed, the fire risk level in the area of exits was unacceptable. In a study conducted by Yarahmadi et al. (18) in the inpatient wards of a hospital, it was found that in the study area, safety principles in building construction and consideration of passive protection systems such as emergency exits were in the poorest level.

One of the most important reasons for the higher level of risk in all areas than the standard level (weaker fire safety) in this study is that in these buildings, the fire safety regulations including automatic fire detection and alarm 
system, sprinkler system, smoke detection and control system, and emergency response program were not available or were defective. This is consistent with the studies by Jahangiri et al. (12) and Mahdinia et al. (16).

On the basis of figure 4 and given that this study was performed on five old commercial buildings (codes $(\mathrm{C}, \mathrm{E}, \mathrm{H}, \mathrm{I}$, and $\mathrm{J}$ ) and five new commercial buildings (codes A, B, D, F, and G), it was found that in all aspects of fire safety, including general safety, fire control, and exits, the older commercial buildings were in a worse position compared to the new ones. This issue indicates that the lack of the applied and regular fire safety measures as well as the lack of supervising bodies during the construction and operation of commercial buildings have caused such problems in the fire safety situation. However, in recent years, due to the development, implementation, and supervision of some fire safety rules and standards and its notification to the executive bodies, including fire organizations, construction engineering organization, and housing and urban development have improved in some areas, but there is still a long way to go to achieve the desired relative fire safety in all buildings.

\section{Acknowledgments}

This study was derived from a M.Sc. thesis on Health, Safety, and Environmental Management at Central Tehran Branch (Electronic), Islamic Azad University with tracking code 1417002. The authors would like to appreciate the officials of the commercial complexes, the director of the Mashhad Municipality Fire and Safety Services Organization, and the deputy director of education and prevention of this organization who cooperated in the implementation of this study.

\section{Conflict of Interests}

Authors have no conflict of interests.

\section{References}

1. Hirschler MM. Fire hazard and fire risk assessment. Conshohocken, PA: ASTM International; 1992.

2. Setareh H, Koohpaee A. Fire risk assessment. Tehran, Iran: Fanavaran Publications; 2011. p. 5-29.

3. Haynes HJ. Fire loss in the United States during 2016. Quincy, MA: National Fire Protection Association (NFPA); 2017.

4. Jahangiri M, Darooghe F, Rajabi F. Fire risk assessment software (Based on NFPA Standard
101). Tehran, Iran: Fanavaran Publications; 2014. p. 3-48. [In Persian].

5. Golmohammadi R. Fire engineering. Tehran, Iran: Fanavaran Publications; 2016. p. 323-43. [In Persian].

6. Society of Fire Protection Engineers (SFPE). Fire risk assessment: Engineering guide. Gaithersburg, MD: SFPE; 2006.

7. Ameri F, Mirzajani M. Statistics of Mashhad City. Mashhad: Mashhad Municipality Planning and Development Department; 2018. https://www.mehrnews.com/news/2761352.

8. National Fire Protection Association. Nfpa 101: Life Safety Code, 2012 Edition. Quincy, MA: NFPA; 2011.

9. Harrington GE. Committee name: Alternative approaches to life safety. Quincy, MA: National Fire Protection Association; 2007.

10. Liu F, Zhao S, Weng M, Liu Y. Fire risk assessment for large-scale commercial buildings based on structure entropy weight method. Saf Sci 2017; 94: 26-40.

11. Mahdinia M, Yarahmadi R, Jafari MJ, Koohpaei AR. Presentation of a software method for use of Risk assessment in Building Fire Safety Measure Optimization. Iran Occup Health 2012; 9(1): 9-16. [In Persian].

12. Jahangiri M, Rajabi F, Darooghe F. Fire risk assessment in selected hospitals of Shiraz University of Medical Sciences in accordance with NFPA 101. Iran Occup Health 2016; 13(1): 99-106. [In Persian].

13. Rezaei M, Givehchi S, Nasrabadi M. Fire risk assessment in hotels and resorts using FRAME (A case study of four-star hotels in Mashhad). Occupational Hygiene and Health Promotion Journal 2017; 1(2): 80-93. [In Persian].

14. Coles A, Wolski A, Lautenberger CW, Dembsey NA. Building code requirements for performance based designs and fire modeling of composite materials. Composites Research Journal 2007; 1: 2.

15. Farshidianfar A. Smoke control engineering in buildings. Mashhad, Iran: Parto Negare Toos Publications; 2017. p. 4-115.

16. Mahdinia M, Yarahmadi R, Jafari M, Koohpaie A, Khazaei M. Fire risk assessment and the effect of emergency planning on risk reduction in a hospital. Qom Univ Med Sci J 2011; 5(3): 71-8. [In Persian].

17. Rajabi F, Jahangiri M, Tavana Shooli F, Rastkar S. Fire risk assessment in multi-story commercial buildings using computerized fire safety evaluation system: A Case Study in Shiraz. J Health Syst Res 2019; 15(1): 74-82. [In Persian].

18. Yarahmadi R, Gholizade A, Jafari M, Koohpaie A, Mahdinia M. Performance assessment, and analysis of national building codes with fire safety in all wards of a hospital. Iran Occup Health 2009; 6(1): 28-36. [In Persian]. 